$\underline{\text { Supporting Information for }}$

\title{
Pt single atom-induced activation energy and adsorption enhancement for ultrasensitive ppb-level methanol gas sensor
}

Qian Rong a, b, Bin Xiao a, Jiyang Zeng a, Ruohan Yu c , Baoye Zi a, Genlin Zhang a, Zhongqi Zhu a, Jin Zhang ${ }^{a^{*}}$, Jinsong Wu ${ }^{\mathrm{c}^{*}}$, Qingju Liu ${ }^{\mathrm{a}^{*}}$

a Yunnan Key Laboratory for Micro/Nano Materials \& Technology, School of Materials and Energy, National Center for International Research on Photoelectric and Energy Materials, Yunnan University, Kunming 650091, China. E-mail: qjliu@ynu.edu.cn.

b School of Chemistry and Environmental Sciences, Qujing Normal University, Qujing 655011, China.

c State Key Laboratory of Advanced Technology for Materials Synthesis and Processing, Nanostructure Research Center, Wuhan University of Technology, 430070, China. E-mail: wujs@whut.edu.cn.

*Corresponding author: Qingju Liu, E-mail: qjliu@ynu.edu.cn. Tel: +86 87165032713

Jin Zhang, E-mail: zhj@ynu.edu.cn.

Jinsong Wu, E-mail: wujs@whut.edu.cn. 


\section{S1. Experimental Section}

\section{S1.1. Synthesis of Ag doped $\mathrm{LaFeO}_{3}$ core-shell sphere}

Ag doped on $\mathrm{LaFeO}_{3}$ core-shell sphere $\left(\mathrm{Ag}-\mathrm{LaFeO}_{3}\right)$ was fabricated using a molecular imprinting technology assisted hydrothermal method, $4.29 \mathrm{~g}$ of $\mathrm{La}\left(\mathrm{NO}_{3}\right)_{3} \cdot 6 \mathrm{H}_{2} \mathrm{O}, 4.04 \mathrm{~g}$ of $\mathrm{Fe}\left(\mathrm{NO}_{3}\right)_{3} \cdot 6 \mathrm{H}_{2} \mathrm{O}$ and $4.20 \mathrm{~g}$ of $\mathrm{C}_{6} \mathrm{H}_{8} \mathrm{O}_{7}$ were dissolved in $90 \mathrm{~mL}$ of deionized DI water, $0.017 \mathrm{~g}$ of $\mathrm{AgNO}_{3}$ was dissolved in $10 \mathrm{~mL}$ of DI water, the above two solutions were mixed and stirred at room temperature for $30 \mathrm{~min}$. An amount of $2.0 \mathrm{~g}$ of $\mathrm{HO}\left(\mathrm{CH}_{2} \mathrm{CH}_{2} \mathrm{O}\right) \mathrm{nH}(\mathrm{PEG})$ was added to this solution. After stirred at $80^{\circ} \mathrm{C}$ for $8 \mathrm{~h}$, the yellow solution in a highpressure microwave chemical reactor was heated at $80{ }^{\circ} \mathrm{C}$ for $6 \mathrm{~h}$ to obtain a mixed sol of $\mathrm{Ag}$ and $\mathrm{LaFeO}_{3}$. Two solutions $10 \mathrm{~mL}$ of $\mathrm{C}_{4} \mathrm{H}_{6} \mathrm{O}_{2}\left(0.036 \times 10^{-4} \mathrm{~mol} / \mathrm{L}\right)$ and $20 \mathrm{~mL}$ of $\mathrm{C}_{8} \mathrm{H}_{12} \mathrm{~N}_{4}\left(0.1 \times 10^{-3} \mathrm{~mol} / \mathrm{L}\right)$ methanol solution were prepared, where the methanol solution of $\mathrm{C}_{4} \mathrm{H}_{6} \mathrm{O}_{2}$ needs to stand for $8 \mathrm{~h}$. a mixed sol of $\mathrm{Ag}$ and $\mathrm{LaFeO}_{3}, \mathrm{C}_{4} \mathrm{H}_{6} \mathrm{O}_{2}$ and $\mathrm{C}_{8} \mathrm{H}_{12} \mathrm{~N}_{4}$ methanol solution were mixed. After 30 min continuous stirring, the mixture solution was reacted at $80{ }^{\circ} \mathrm{C}$ for $12 \mathrm{~h}$ in a water-bathing to obtain $\mathrm{Ag}$ doped on $\mathrm{LaFeO}_{3}$ molecularly imprinted polymer. The $\mathrm{Ag}$ doped on $\mathrm{LaFeO}_{3}$ molecularly imprinted polymer was transferred to a reaction kettle to react for $24 \mathrm{~h}$ at $100^{\circ} \mathrm{C}$, the resulting brown precipitation was washed third via precipitation with methanol and DI water, the $\mathrm{Ag}-\mathrm{LaFeO}{ }_{3}$ was obtained by freeze-drying at $-45^{\circ} \mathrm{C}$ for $24 \mathrm{~h}$.

\section{S1.2. Synthesis of Pt single atom stabilized on $\mathrm{Ag}-\mathrm{LaFeO}_{3} @ \mathrm{ZnO}$}

$1.19 \mathrm{~g}$ of $\mathrm{Zn}\left(\mathrm{NO}_{3}\right)_{2} \cdot 6 \mathrm{H}_{2} \mathrm{O}$ was dissolved into the $15 \mathrm{~mL}$ methanol under stirring. 1.31 $\mathrm{g}$ of $\mathrm{C}_{4} \mathrm{H}_{6} \mathrm{~N}_{2}$ was dissolved in $100 \mathrm{~mL}$ of methanol solution. The two solutions were then mixed and form a homogenous solution. $2.54 \mathrm{~g}$ of $\mathrm{Ag}-\mathrm{LaFeO}_{3}$ was added and kept stirring at room temperature for $10 \mathrm{~min}$. The five same solutions were prepared according to the same procedure. Different mass ratios of $\mathrm{H}_{2} \mathrm{PtCl}_{6} \cdot 6 \mathrm{H}_{2} \mathrm{O}(0.75 \%, 0.50 \%, 0.25 \%, 0.15 \%$ and $0.10 \%$ ) were added to the five mixed solutions separately and stirred at room temperature for $30 \mathrm{~min}$. The solution was transferred to a Teflon reactor and heated to 120 ${ }^{\circ} \mathrm{C}$ for $4 \mathrm{~h}$. The brown precipitate was collected by centrifugation and washed with DMF and methanol. After freeze-drying, Pt single atom stabilized on Ag- $\mathrm{LaFeO}_{3} @ \mathrm{ZnO}$ coreshell sphere $\quad\left(\mathrm{Ag}-\mathrm{LaFeO}_{3} @ \mathrm{ZnO}-0.75 \% \mathrm{Pt}, \quad \mathrm{Ag}-\mathrm{LaFeO}_{3} @ \mathrm{ZnO}-0.50 \% \mathrm{Pt}, \quad \mathrm{Ag}-\right.$ 
$\mathrm{LaFeO}_{3} @ \mathrm{ZnO}-0.25 \% \mathrm{Pt}, \mathrm{Ag}-\mathrm{LaFeO}_{3} @ \mathrm{ZnO}-0.15 \% \mathrm{Pt}$ and Ag-LaFeO 3 @ ZnO-0.10\%Pt) was obtained.

\section{S1.3. Gas sensor fabrication and measurements}

The Ag-LaFeO $3 @ \mathrm{ZnO}-\mathrm{Pt}$ powders with different ratios of $5 \mathrm{mg}$ were dispersed in the $5 \mathrm{~mL}$ of printing oil to form a uniform paste, respectively. The screen-printing plate and squeegee were rinsed with ethanol and dried. The slimy Ag- $\mathrm{LaFeO}_{3} @ \mathrm{ZnO}-\mathrm{Pt}$ were printed in the $4 \mathrm{~mm}$ round shaper electrode of the substrate using mechanical screen-printing technology (Figure S1a). The prepared samples were placed in a tube furnace filled with an oxygen atmosphere, annealed at $400{ }^{\circ} \mathrm{C}$ for $2 \mathrm{~h}$ to remove printing oil, and cooled to room temperature. Afterward, the sample was installed on a four-channel gas sensitivity tester and aged for $24 \mathrm{~h}$ in air atmosphere of $300{ }^{\circ} \mathrm{C}$. Observe the change of resistance in real-time, after the curve stabilizes, the gas sensitivity test can be performed. The sensor response was estimated through the resistance relative change of the sensor before and after injection of the target gas. The sensor was working at different operating temperatures. To confirm the selectivity of the sensors, the response of sensors to $5 \mathrm{ppm}$ of methanol, ethanol, acetone, benzene and gasoline were also investigated, respectively. The working schematic diagram of the device was shown in Figure S1. The detection limit (LD) was a main parameter for evaluating the actual application of a sensor, it defines the minimum amount that the sensor can sense. The detection limit (LD) was calculated using the formula $L D=3$ $\mathrm{R}_{\mathrm{msd}} / \mathrm{S}$, where $\mathrm{R}_{\mathrm{msd}}$ is the root mean square deviation and $\mathrm{S}$ is the slope of the calibration curve.

\section{S1.4. Density Functional Theory details}

We have employed the first-principles to perform spin-polarization density functional theory (DFT) calculations within the generalized gradient approximation (GGA) using the Perdew-Burke-Ernzerhof (PBE) formulation ${ }^{1,2}$. We have chosen the projected augmented wave (PAW) potentials to describe the ionic cores and take valence electrons into account using a plane wave basis set with a kinetic energy cutoff of $450 \mathrm{eV}$. Partial occupancies of the Kohn-Sham orbitals were allowed using the Gaussian smearing method and a width of $0.05 \mathrm{eV}$. The electronic energy was considered self-consistent when the energy change was 
smaller than 10-5 eV. A geometry optimization was considered convergent when the energy change was smaller than $0.05 \mathrm{eV} \AA^{-1}$. In addition, the $U$ schemes need to be applied to these metal atoms ${ }^{3}$. The vacuum spacing in a direction perpendicular to the plane of the structure was $15 \AA$ for $\mathrm{LaFeO}_{3}$ surface and interface. The Brillouin zone integration was performed using $2 \times 2 \times 1$ Monkhorst-Pack k-point sampling for a structure. Finally, the adsorption energies $\left(E_{a d s}\right)$ were calculated as $E_{a d s}=E_{a d / s u b}-E_{a d}-E_{\text {sub }}$, where $E_{a d / s u b}, E_{a d}$, and $E_{\text {sub }}$ were the total energies of the optimized adsorbate/substrate system, the adsorbate in the structure, and the clean substrate, respectively ${ }^{4}$. In our work, the $E_{a d / s u b}$ is the total energy of $\mathrm{Ag}-\mathrm{LaFeO}_{3} @ \mathrm{ZnO}$ or $\mathrm{Ag}-\mathrm{LaFeO}_{3} @ \mathrm{ZnO}-\mathrm{Pt}$ with molecular adsorbed. And the $\mathrm{E}_{\mathrm{ad}}$ are the energies of molecular $\left(\mathrm{O}_{2}\right.$, methanol, formaldehyde or xylene), $\mathrm{E}_{\text {sub }}$ is the energy of the $\mathrm{Ag}-\mathrm{LaFeO}_{3} @ \mathrm{ZnO}$ or $\mathrm{Ag}-\mathrm{LaFeO}_{3} @ \mathrm{ZnO}-\mathrm{Pt}$. In addition, the Density functional theory had also been employed to describe the transformation pathway in our systems. The free energies $(G)$ of different intermediates are defined as $G=E_{i}-E_{\text {reactant }}\left(E_{i}\right.$ is the energy of intermediates and $E_{\text {reactant }}$ is the total energy of reactants) and finally obtained by $\mathrm{G}=\mathrm{E}_{\text {total }}+\mathrm{E}_{\mathrm{ZPE}}-\mathrm{T}_{\mathrm{S}}$, where $\mathrm{E}_{\text {total }}, \mathrm{E}_{\mathrm{ZPE}}$, and $\mathrm{T}_{\mathrm{S}}$ are the ground-state energy, zero-point energies, and entropy terms, respectively, with the latter two taking vibration frequencies from DFT 5. The transition state had been evaluated using the climbing nudged elastic band (CI-NEB) methods. The bottom layers will be fixed in our surface and interface structure. The $\mathrm{ZnO}$ (102) surface and $\mathrm{LaFeO}_{3}$ (110) surface has been established from the bulk structure.

\section{S1.5. Materials characterization}

FESEM was performed on a Hitachi-S3400N at an accelerating voltage of $3 \mathrm{kV}$, to study the morphology of the $\mathrm{Ag}-\mathrm{LaFeO}_{3}$ and $\mathrm{Pt}$ atoms stabilized on $\mathrm{Ag}-\mathrm{LaFeO}_{3} @ \mathrm{ZnO}$. The microstructure and elemental mapping of materials were characterized by TEM and HRTEM images at an acceleration voltage of $300 \mathrm{kV}$ and EDX. The phase formation and crystal structure were observed using XRD with $\mathrm{Cu}$ Ka radiation source $(\lambda=1.5406 \AA)$ at $25 \mathrm{~mA}$ and $35 \mathrm{kV}$. The oxidation states and chemical bonding between the elements of materials were carried out using X-ray photoelectron spectroscopy (XPS, K-Alpha ${ }^{+}$) using a Thermo fisher Scientific, with a vacuum of $\sim 2 \times 10^{-7} \mathrm{mba}$, and $\mathrm{A} 1 \mathrm{~K} \alpha$ as the exciting source. The functional group was identified by fourier transform infrared spectroscopy (FT-IR, 
FTS-40). The BET surface area (SBET) of material was measure from Quadrasorb-evo instrument.

\section{S1.6. Calculation of low limit of detection (LLD) of the sensors}

The sensitivity and the root-mean-square (RMS) deviation at the baseline are used to obtain noise level and the LLD of the sensors. According to the International Union of Pure and Applied Chemistry (IUPAC), as the detection signal is three times higher than the instrument noise level, the theoretical LLD of the sensor can be obtained by correlation calculation ${ }^{6}$. A linear fit of the response to the target gas concentration curve is performed in the linear region, and then the slope $(\mathrm{S})$ is obtained. Then the root-mean-square deviation (RMS) and LLD are calculated using the formulas equation (1) and (2):

$$
\begin{gathered}
R M S\left(p p m^{-1}\right)=\sqrt{\left(\sum\left(X_{i}-X\right)^{2} /(N-1)\right)} \\
L L D(p p m)=3 R M S / S
\end{gathered}
$$




\section{S2. Supplementary Figures}

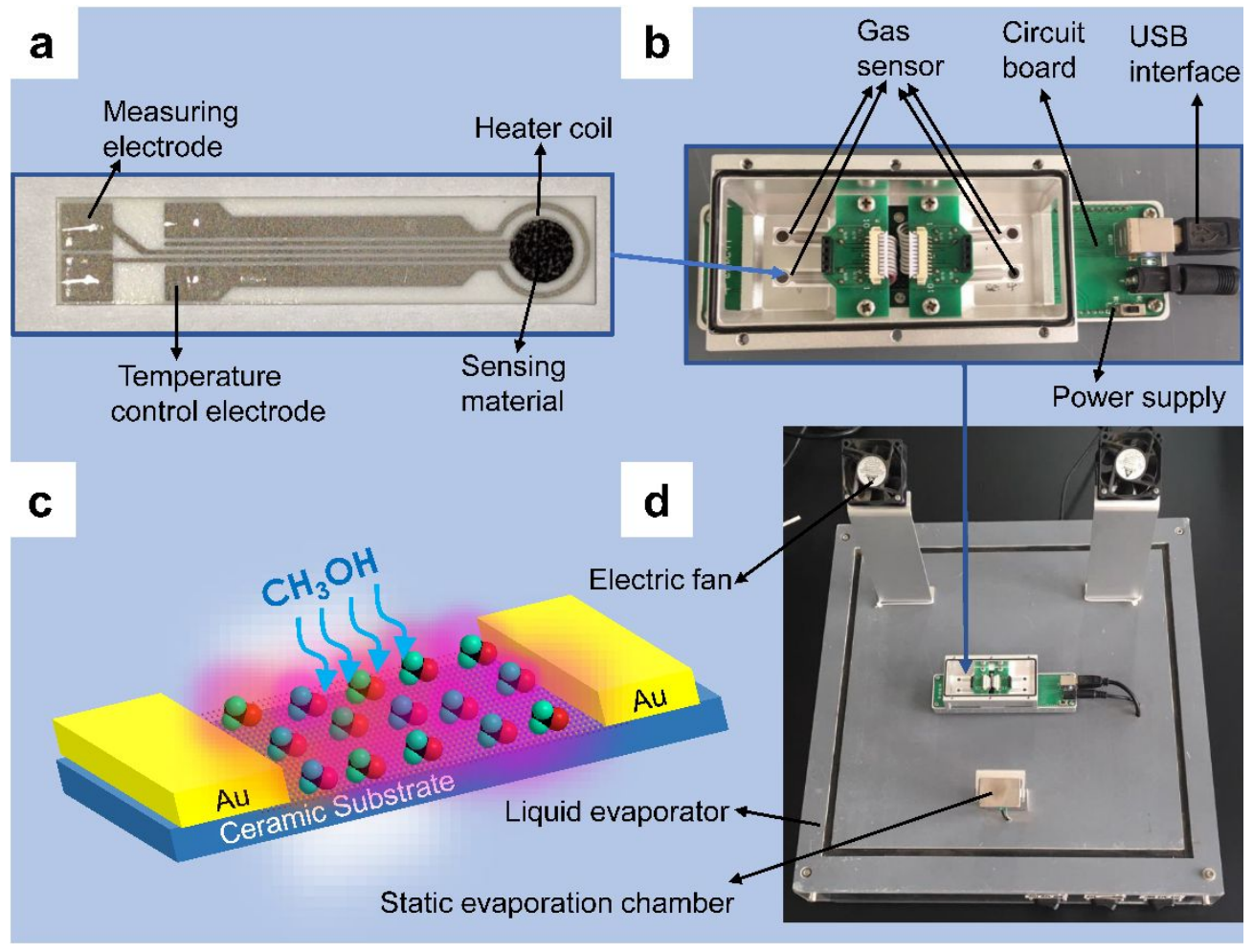

Figure S1. Gas sensor and gas sensor test platform. (a) Samples with printed materials. (b) Aluminum alloy test cavity. (c) Schematic diagram of device operation. (d) Static evaporation chamber. 

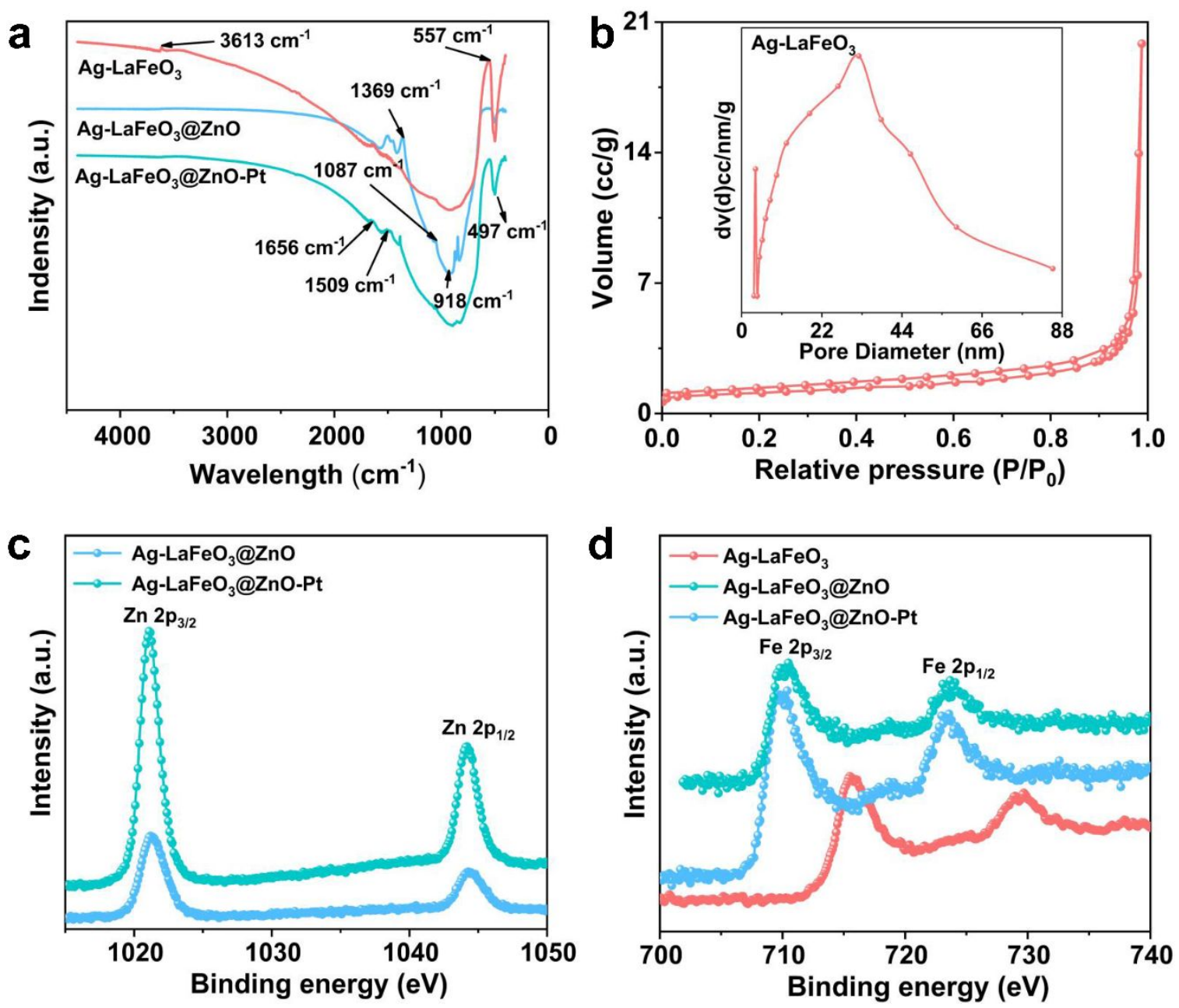

Figure S2. Structural characterizations of $\mathrm{Ag}-\mathrm{LaFeO}_{3}, \mathrm{Ag}-\mathrm{LaFeO}_{3} @ \mathrm{ZnO}$ and Ag$\mathbf{L a F e O}_{3} @ Z$ ZnO-Pt. (a) FT-IR spectra of Ag-LaFeO,$A g-\mathrm{LaFeO}_{3} @ \mathrm{ZnO}$ and Ag$\mathrm{LaFeO}_{3} @ \mathrm{ZnO}-\mathrm{Pt}$. (b) Nitrogen adsorption and desorption isotherm and pore size distribution curve of $\mathrm{Ag}-\mathrm{LaFeO}_{3}$. (c) $\mathrm{Zn} 2 \mathrm{p}$ XPS spectrum of $\mathrm{Ag}-\mathrm{LaFeO}_{3} @ \mathrm{ZnO}$ and Ag$\mathrm{LaFeO}_{3} @ \mathrm{ZnO}-\mathrm{Pt}$. (d) Fe 2p XPS spectrum of Ag-LaFeO 3 @ZnO and Ag-LaFeO ${ }_{3} @ \mathrm{ZnO}-$ Pt. 

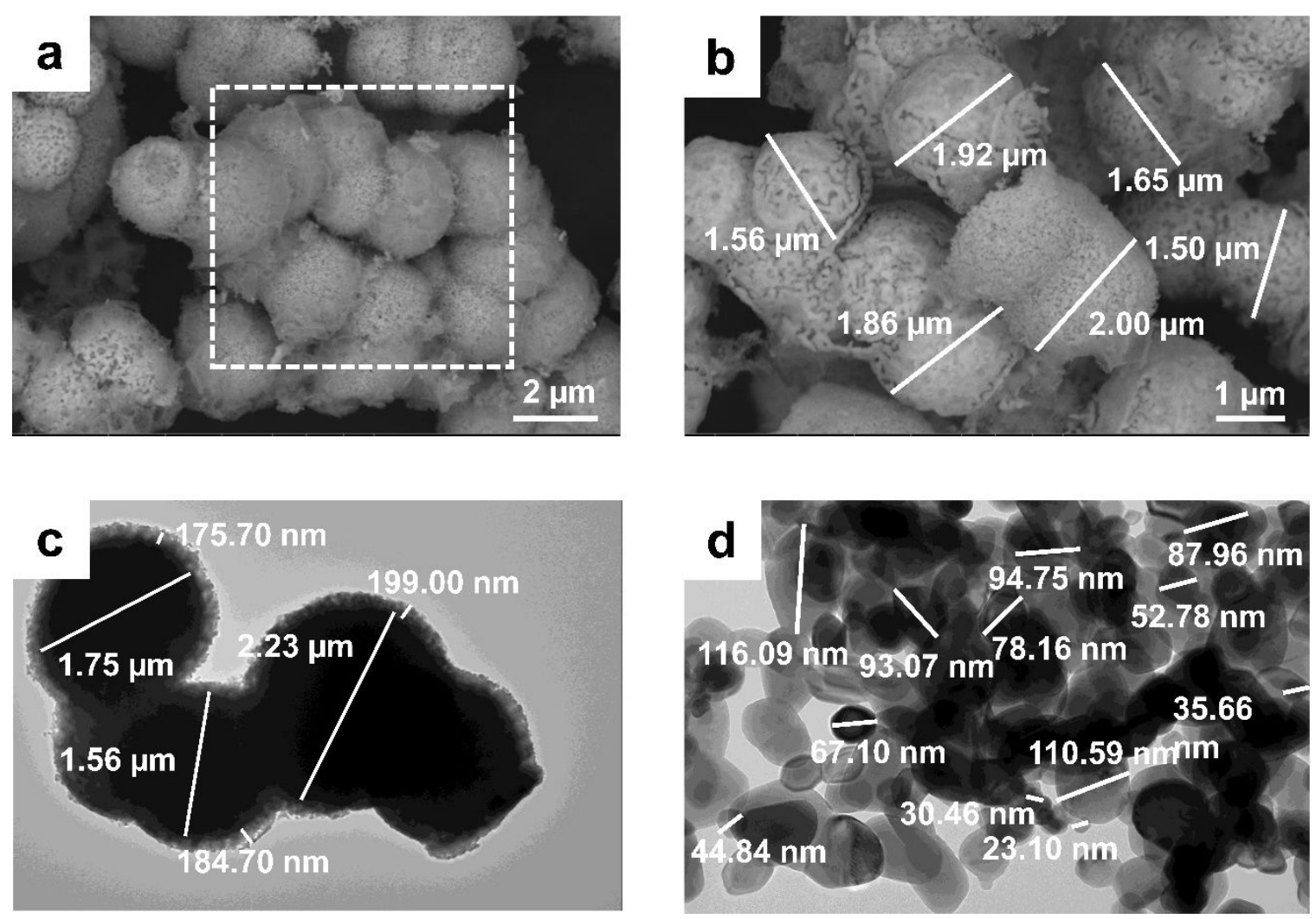

Figure S3. Electron microscopy characterizations of $\mathrm{Ag}-\mathrm{LaFeO}_{3} @ \mathrm{ZnO}-\mathrm{Pt}$ sample, (a and b) SEM image, (c) TEM image and (d) HRTEM image. 

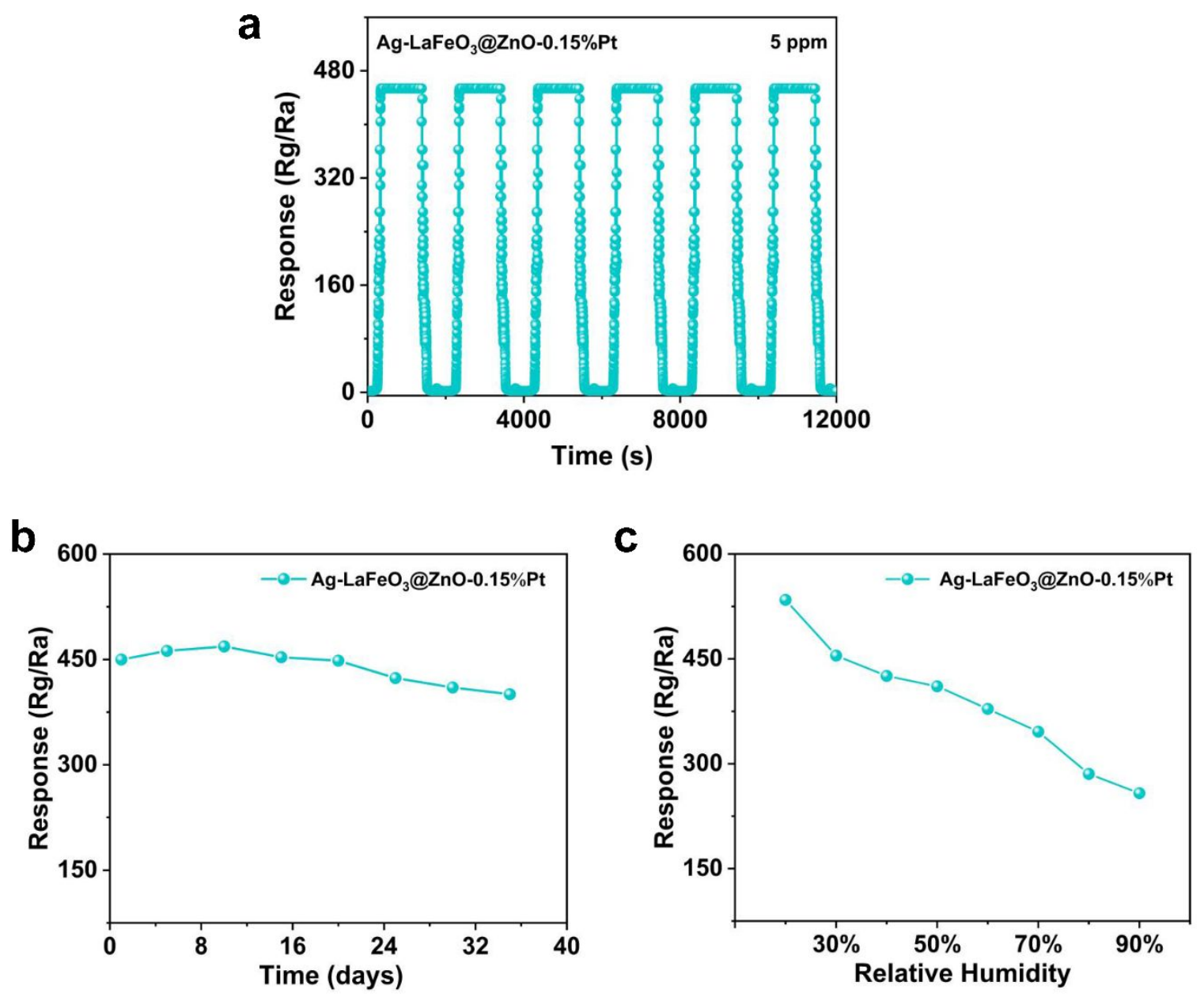

Figure S4. Gas sensitivity performance of Ag- $\mathrm{LaFeO}_{3} @ Z$ ZnO-Pt. (a) Dynamic cycle stability of Ag-LaFeO $@$ @ ZnO-Pt to 5 ppm methanol gas. (b) The stability of Ag$\mathrm{LaFeO}_{3} @ \mathrm{ZnO}-\mathrm{Pt}$ to 5 ppm methanol gas in 35 days (measured every 5 days). (c) The gas sensitivity of $\mathrm{Ag}-\mathrm{LaFeO}_{3} @ \mathrm{ZnO}-\mathrm{Pt}$ to 5 ppm methanol gas under 20\%-90\% RH and optimal working temperature of $86^{\circ} \mathrm{C}$. 

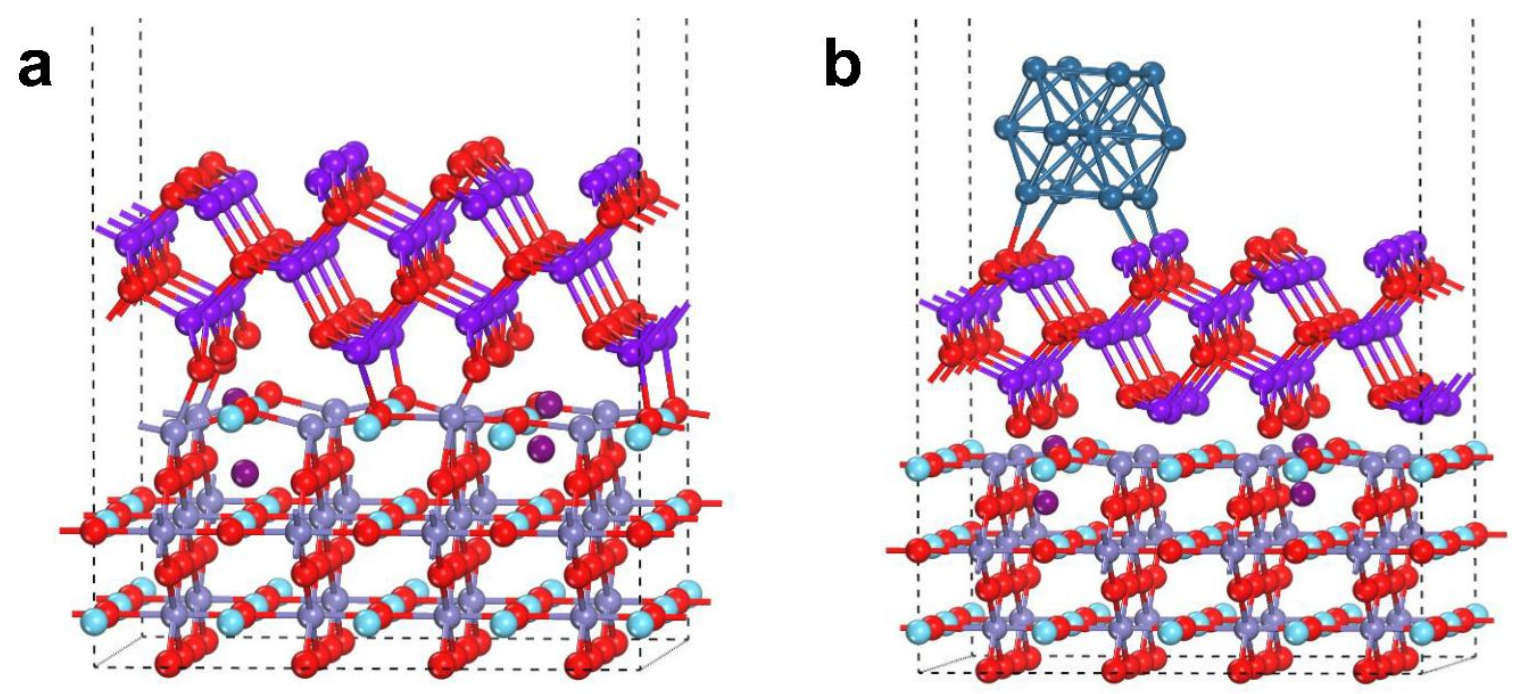

\section{Fe○o $\bigcirc$ La $\odot$ Ag $\odot \mathbf{z n} \odot \mathbf{P t}$}

Figure S5. Structure diagrams of $\mathrm{Ag}-\mathrm{LaFeO}_{3} @ \mathrm{ZnO}$ (a) and $\mathrm{Ag}-\mathrm{LaFeO}{ }_{3} @ \mathrm{ZnO}-\mathrm{Pt}(\mathrm{b})$. 

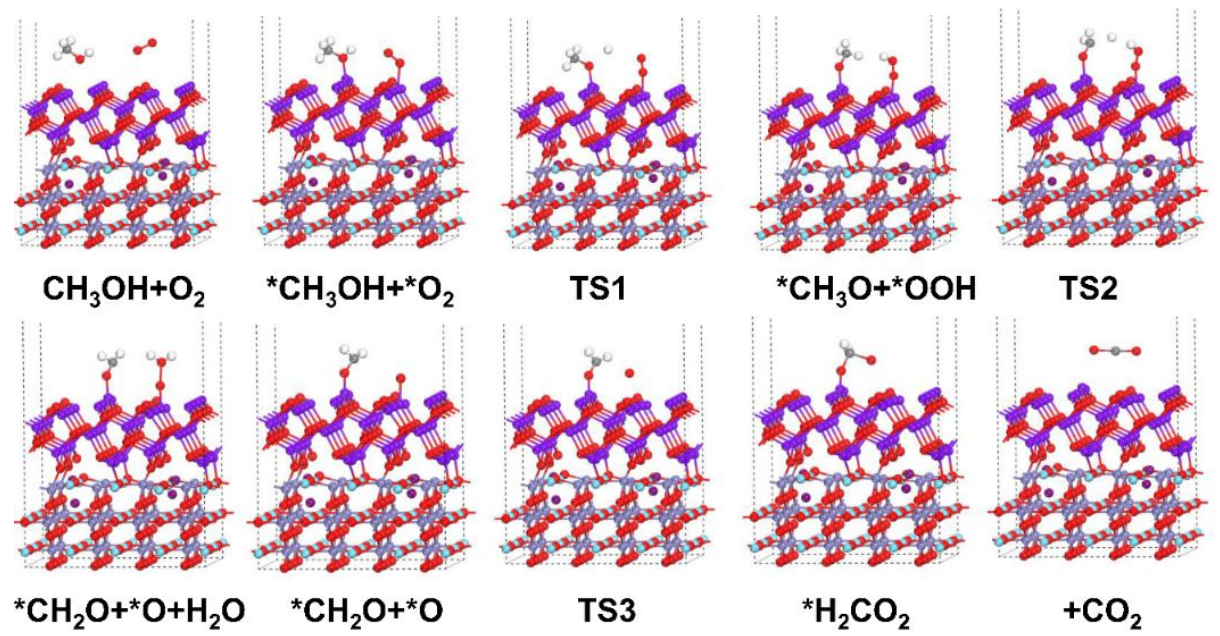

Figure S6. The mechanism of the oxidation reaction for methanol gas on Ag$\mathrm{LaFeO}_{3} @ \mathrm{ZnO}$. Structure diagram of $\mathrm{Ag}-\mathrm{LaFeO}_{3} @ \mathrm{ZnO}$ reacting with ions at different stages. 

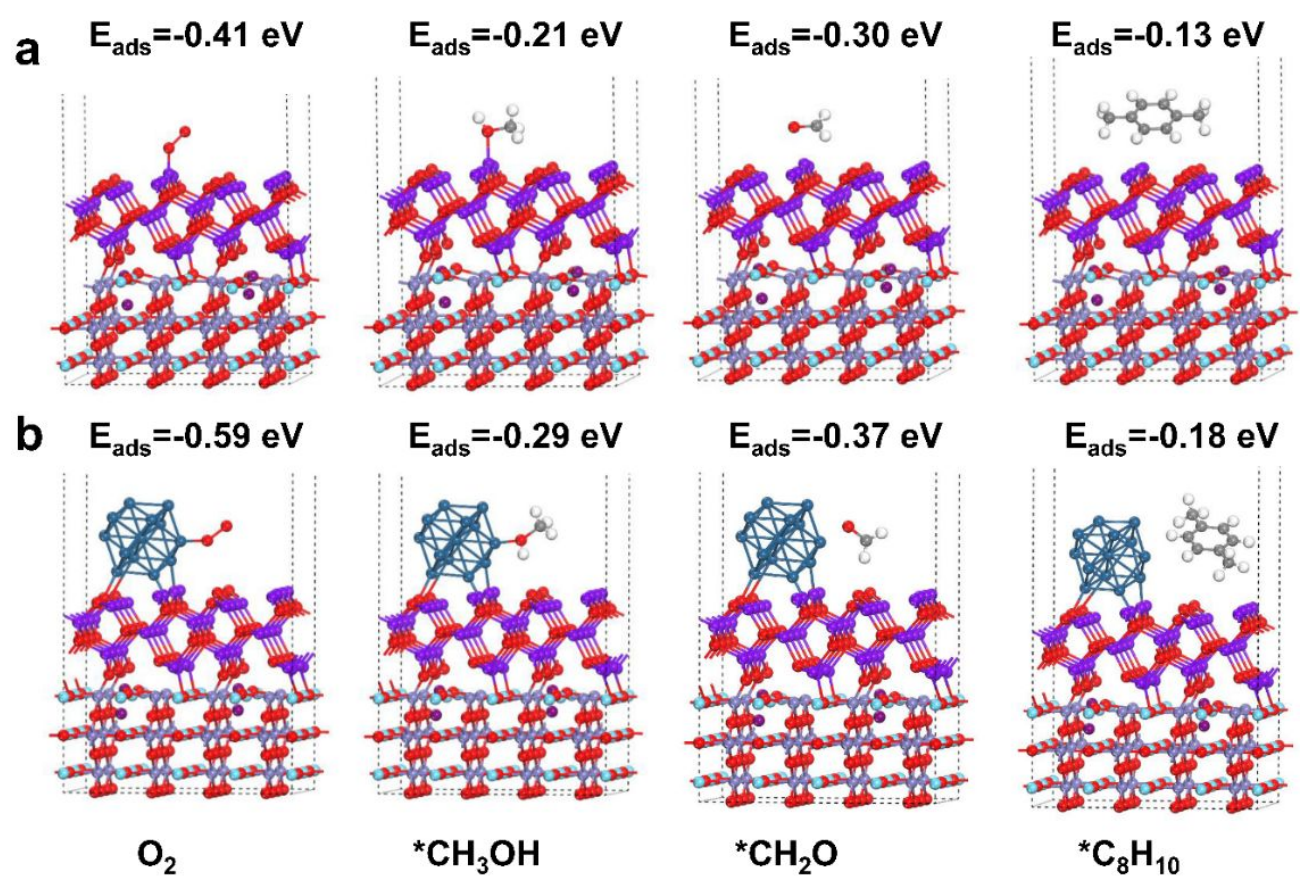

Figure S7. Calculation of adsorption energy. (a) The structure diagram of Ag$\mathrm{LaFeO}_{3} @ \mathrm{ZnO}$ reacting with different gases $\left(\mathrm{O}_{2}\right.$, methanol, formaldehyde and xylene), and the adsorption energy of different gases on the Ag- $\mathrm{LaFeO}_{3} @ \mathrm{ZnO}$ surface. (b) The structure diagram of $\mathrm{Ag}-\mathrm{LaFeO}_{3} @ \mathrm{ZnO}-\mathrm{Pt}$ reacting with different gases $\left(\mathrm{O}_{2}\right.$, methanol, formaldehyde and xylene), and the adsorption energy of different gases on the Ag$\mathrm{LaFeO}_{3} @ \mathrm{ZnO}-\mathrm{Pt}$ surface. 


\section{S3. Supplementary Tables}

Table S1 Comparison of key sensing parameters of various methanol gas sensors in this study as well as the recently-reported literature.

\begin{tabular}{|c|c|c|c|c|c|}
\hline Materials & $\begin{array}{c}\text { Methanol } \\
\text { (ppm) }\end{array}$ & $\begin{array}{c}\text { Working } \\
\text { temperature } \\
\left({ }^{\circ} \mathrm{C}\right)\end{array}$ & $\mathrm{t}_{\mathrm{res}} \mathrm{t}_{\mathrm{rec}}(\mathrm{s})$ & $\begin{array}{l}\text { Response } \\
\qquad\left(R_{g} / R_{a}\right)\end{array}$ & References \\
\hline $\begin{array}{l}\mathrm{Ag}-\mathrm{LaFeO}_{3} \\
\text { @ } \mathrm{ZnO}-\mathrm{Pt}\end{array}$ & 5 & 86 & $81.0 / 79.0$ & 453.8 & This work \\
\hline Pd-doped $\mathrm{SnO}_{2}$ & 5 & 80 & $102 /$ & 7.5 & {$[7]$} \\
\hline $\begin{array}{l}\mathrm{Co}_{3} \mathrm{O}_{4} / \text { single- } \\
\text { walled carbon } \\
\text { nanotube }\end{array}$ & 35 & 300 & l & 9.0 & [8] \\
\hline $\mathrm{Pt} 1-\mathrm{Fe}_{2} \mathrm{O}_{3}-\mathrm{ox}$ & 100 & 280 & $30 / 24$ & 102.4 & {$[9]$} \\
\hline $\begin{array}{l}\mathrm{SnO}_{2} \\
\text { hierarchical } \\
\text { nanoflowers }\end{array}$ & 1 & 200 & $1 / 3$ & 1.6 & [10] \\
\hline $\mathrm{Pd}-\mathrm{CeO}_{2}$ & 100 & 200 & $1 / 5$ & 6.95 & [11] \\
\hline La-doped $\mathrm{SnO}_{2}$ & 75 & 200 & $12 / 7$ & 29.5 & [12] \\
\hline $\begin{array}{l}\mathrm{SnO}_{2} \\
\text { nanosheet/SiC }\end{array}$ & 100 & 500 & $3 / 9$ & 3 & [13] \\
\hline Porous $\mathrm{In}_{2} \mathrm{O}_{3}$ & 20 & 370 & $10 / 10$ & 10 & {$[14]$} \\
\hline $\mathrm{SnO}_{2}-\mathrm{ZnO}$ & 10 & 350 & $20 / 40$ & 9 & {$[15]$} \\
\hline$\alpha-\mathrm{Fe}_{2} \mathrm{O}_{3} / \mathrm{NiO}$ & 100 & 300 & $1 / 12$ & 8 & {$[16]$} \\
\hline
\end{tabular}




\section{References}

(1) Kresse, G.; Furthmuller, J. Efficient iterative schemes for ab initio total-energy calculations using a plane-wave basis set. Phys. Rev. B 1996, 54, 11169-11186.

(2) Perdew, J. P.; Burke, K.; Ernzerhof M. Generalized gradient approximation made simple. Phys. Rev. Lett. 1996, 77, 3865-3868.

(3) Peterson, A. A.; Nørskov J. K. Activity descriptors for $\mathrm{CO}_{2}$ electroreduction to methane on transition-metal catalysts. J. Phys. Chem. Lett. 2012, 3, 251-258.

(4) Gao, S.; Sun, Z. T.; Liu, W.; Jiao, X. C.; Zu X. L. Atomic layer confined vacancies for atomic-level insights into carbon dioxide electroreduction. Nat. Commun. 2017, 8, 14503. Dol: $10.1038 /$ ncomms 14503

(5) Xiaowa, N.; Monica, R. E.; Michael, J. J.; Aravind A. Selectivity of $\mathrm{CO}_{2}$ reduction on copper electrodes: the role of the kinetics of elementary steps. Angew. Chem. Int. Ed. 2013, 52, 2459-2462.

(6) Fubo, G.; Yuzhen, C.; Dongmei, H.; Song, H.; Maria, F.; Zhihua, W.; Atomically dispersed Pt (II) on $\mathrm{WO}_{3}$ for highly selective sensing and catalytic oxidation of triethylamine. Appl. Catal. B: Environ. 2019, 256, 117809. Dol: 10.1016/j.apcatb.2019.117809

(7) Van den Broek, J.; Abegg, S.; Pratsinis, S. E.; Güntner A. T. Highly selective detection of methanol over ethanol by a handheld gas sensor. Nat. Commun. 2019, 10, 4220. Dol: 10.1038/s41467-019-12223-4

(8) Chinh, N. D., Hung, N. M.; Majum, S.; Kim, C. J.; Kim, D. J. Hole-supply-ratecontrolled methanol-gas-sensing reaction over p-type $\mathrm{Co}_{3} \mathrm{O}_{4} /$ single-walled carbon nanotube hybrid structures. Sens. Actuators B, 2021, 326, 128956. Dol: 10.1016/j.snb.2020.128956

(9) Li, Q. H.; Li, Z.; Zhang, Q. H.; Zheng, L. R.; Yan, W. S. Porous $\gamma-\mathrm{Fe}_{2} \mathrm{O}_{3}$ nanoparticle decorated with atomically dispersed platinum: Study on atomic site structural change and gas sensor activity evolution. Nano Res. 2021, 14, 1435-1442.

(10) Song, L. M.; Zhao, B.; Ju, X. G.; Liu, L.; Gong, Y. M. Comparative study of methanol gas sensing performance for $\mathrm{SnO}_{2}$ nanostructures by changing their morphology. Mat. Sci. Semicon. Proc 2020, 111, 104986. Dol: 10.1016/j.mssp.2020.104986 
(11) Hu, Q.; Huang, B. Y.; Li, Y.; Zhang, S. M.; Zhang, Y. X. Methanol gas detection of electrospun $\mathrm{CeO}_{2}$ nanofibers by regulating $\mathrm{Ce}^{3+} / \mathrm{Ce}^{4+}$ mole ratio via Pd doping. Sens. Actuators B, 2020, 307, 127638. Dol: 10.1016/j.snb.2019.127638

(12) Chen, Y.; Dong, Z. G.; Xue, X. X.; Chen, S.; Lv Y. High-sensitivity and high-selectivity detection of methanol based on La-doped $\mathrm{SnO}_{2}$ sensor. Appl. Phys. A 2020, 126, 299. Dol: 10.1007/s00339-020-03478-6

(13) Wang, B.; Wang, Y. D.; Lei, Y. P.; Xie, S.; Wu, N. Vertical $\mathrm{SnO}_{2}$ nanosheet @SiC nanofibers with hierarchical architecture for high-performance gas sensors. J. Mater. Chem. C, 2016, 4, 295-304.

(14) Li, Y. S.; Xu, J.; Chao, J.; Chen, D.; Ouyang S. High-aspect-ratio single-crystalline porous $\mathrm{In}_{2} \mathrm{O}_{3}$ nano-belts with enhanced gas sensing properties. J. Mater. Chem. 2011, 21, 12852-12857.

(15) Tang, W.; Wang, J.; Yao, P.; Li X. Hollow hierarchical $\mathrm{SnO}_{2}-\mathrm{ZnO}$ composite nanofibers with hetero-structure based on electro spinning method for detecting methanol. Sens. Actuators. B, 2014, 192, 543-549.

(16) Wang, C.; Cheng, X. Y.; Zhou, X.; Sun, P.; Hu X. L. Hierarchical $\alpha-\mathrm{Fe}_{2} \mathrm{O}_{3} / \mathrm{NiO}$ composites with a hollow structure for a gas sensor. ACS Appl. Mater. Inter 2014, 6 , 12031-12037. 